\title{
LA ORGANIZACION TERRITORIAL DE LA HERMANDAD GENERAL (1476-1498)
}

\author{
POR \\ José MARÍA SÁnCHez Benito \\ (Colegio Universitario de Cuenca)
}

La Hermandad general impulsada por los Reyes Católicos partía de una ya larga tradición recogiendo el amplio cúmulo de experiencias que las sucesivas formaciones hermandinas habian venido desarrollando durante siglos. Los recientes ensayos surgidos a lo largo del reinado de Enrique IV proporcionaban un ejemplo inmediato, y es acertado decir que los nuevos monarcas aprovecharon una idea "que flotaba en el ambiente" (1) y que muchos habian considerado adecuada para salvaguardar valores que como la propiedad y la seguridad quedaban seriamente cuestionados, especialmente, en etapas de inestabilidad política, aun siendo, por otra parte, imprescindibles para el desenvolvimiento económico de las ciudades castellanas, dispuestas a recurrir a la fórmula hermandina con cierta asiduidad desde tiempos que al iniciarse el último cuarto del siglo XV podían considerars $\mathrm{y}$ ya casi remotos.

Sin embargo, la organización proyectada desde los primeros momentos del acceso al poder de Isabel y Fernando aunque asumía todo lo que era fundamental al concepto hermandad, tal y como por entonces se entendia: solidaridad de ciudades con una finalidad prioritaria de seguridad más allá de los muros de las mismas, mostró pronto, en el curso de las juntas celebradas en el verano de 1476, nuevas vertientes que hacían de la entidad impulsada por la Corona algo claramente novedoso, con objetivos militares y fiscales al servicio de aquélla.

Pero, antes que nada, y ya desde comienzos de 1475, la corporación aparecía como una iniciativa regia expresada a través de ordenamientos dados por la monarquía mediante los cuales ésta asociaba a las diferentes tierras, pueblos y núcleos urbanos en una entidad suscitada desde el poder $y$, naturalmente, para el poder, dando así la vuelta a la tradición hermandina que se basaba en la iniciativa ciudadana y hacía de la organización constituida en cada una de ellas algo independiente (2) coordinándose luego entre sí.

Por consiguiente, la nueva hermandad desde el principio resultaba peculiar: la adaptación de una fórmula institucional sólidamente enraizada en Castilla a los intereses de los soberanos para

(1) Como ha dicho SUÁREz FERNÁNDEZ, L.: «La España de los Reyes Católicos», en Historia de España, dirigida por R. Menéndez Pidal, XVII-I, Madrid, 1978, p. 238.

(2) LUNENFELD, M.: The council of the Santa Hermandad, Miami, 1970, p. 65. 
los cuales se convertía en un instrumento potencialmente muy útil desde diferentes puntos de vista: militar, hacendístico, pero también desde la óptica político-administrativa como nuevo ámbito de toma de decisiones y de ejercicio del poder cuyo alcance llegaba a la totalidad del reino, es decir, se trataba de un fuerte medio de centralización en manos de la Corona que encargó las más importantes tareas directivas del mismo a un pequeño número de personajes, por lo demás bien conocidos, próximos a los reyes y de su confianza, que se encargaron directamente de la gestión del organismo.

Se ha hablado muchas veces de la organización militar de la Hermandad nueva, dispuesta a partir de la Junta de Cigales y consolidada en sucesivos ordenamientos, del mismo modo, ha sido suficientemente destacado el papel de la contribución armada hermandina en la guerra de Granada (3), de tal manera que esta finalidad de la institución: la formación de un ejército a disposición de la Corona y la disponibilidad de los medios económicos para sostenerlo no pueden ofrecer la menor duda. Además de ello la corporación como instrumento de centralización, tal y como hemos indicado, supone un nuevo ámbito de la administración, o, dicho de otra forma si se quiere, una nueva esfera para el poder real dirigida por fieles funcionarios $y$ a través de organismos fáciles de controlar, una esfera que superaba y por ello resultaba totalmente ajena a otras autoridades como, principalmente, las ciudades más importantes, antaño protagonistas y ahora meros comparsas crecientemente opuestas a una corporación que les originaba gastos y restaba influencia (4).

En este sentido, la Hermandad adoptó un esquema territorial acorde con su carácter centralizador, mediante la disposición de las llamadas provincias. El primitivo ordenamiento de febrero de 1475 (5) no incluía una organización concreta del territorio, se decía alli: "...sean fechas hermandades por vosotros en todas las çibdades e villas e logares de los dichos nuestros regnos e señorios asy realengos como de señorios e de hordenes e de behetrias, cada

(3) Sobre el tema, LADERO QUESADA, M. A.: Castilla y la conquista del reino de Granada, Valladolid, 1967, 2. ${ }^{a}$ ed., Granada, 1987; también ABELLÁN PÉREZ. J. M. $.^{a}:$ "Contribución humana de la Hermandad de Murcia a la guerra de Granada», en Miscelánea, Medieval Murciana, $x, 1983$, pp. 19-45.

(4) El caso de Burgos ha sido estudiado por SERRANO. L.: Los Reyes Católicos y la ciudad de Burgos desde 1451 a 1492, Madrid, 1943, pp. 167-87. Más reciente es el trabajo de GuERRERO NAVARRETE Y.: "La Hermandad de 1476 y Burgos. Un factor decisivo en la transformación del poder municipal a fines de la Edad Median, en Anuario de Estudios Medievales, 16, 1986, pp. 533-55.

(5) A.M. de Cuenca, leg. 16 exp. 4 y leg. 1145 exp. 2. Sobre este ordenamiento y los orígenes de la Hermandad mi trabajo Consideraciones sobre los orígenes de la Hermandad de ios Reyes Católicos. Un ordenamiento inédito de 1475 (en prensa). 
çibdad e villa por sy e con su tierra e termino e juridiçion para entre ellos mismos e eso mismo para con las otras tierras e partidos e comarcas....1, o sea, que se tomaba como unidad el término jurisdiccional de las villas y ciudades, pero más adelante aparece ya el término provincia, indicando: "...todas las dichas prouinçias, merindades e valles e çibdades e villas e logares de los dichos nuestros regnos, cada cibdad e villa por sy e por su tierra e terminio fagan la dicha Hermandad vnas con otras e otras con otras e todas juntas vnas con otras...e que la vayan a faser e jurar cada pueblo a la cabeça del arçobispado e obispado, arçedianadgo e merindad...l, con lo que respetándose la unidad tradicional del núcleo urbano con su tierra se añadía un nuevo principio de orden al establecerse la obligatoriedad de que las diferentes poblaciones acudiesen a la cabecera de su correspondiente arzobispado, obispado, arcedianazgo o merindad a fin de asegurar su adhesión a la institución mediante juramento, creándose así una red de vinculaciones en torno a ciertas ciudades más importantes pero dentro siempre de criterios tradicionales similares a los utilizados en las anteriores hermandades de época de Enrique IV, utilizando como base antiguas agrupaciones territoriales sin incluir elementos nuevos.

Surge así una forma de jerarquización que sin embargo desborda a los diferentes núcleos urbanos y sus tierras dependientes reuniéndolos en unidades de mayor amplitud geográfica y fines determinados. No obstante, las ordenanzas de 1475 no tuvieron continuidad retrasándose más de un año la verdadera constitución y dotación institucional de la entidad.

El ordenamiento presentado ante los procuradores en las Cortes de Madrigal, muy similar en su tenor a las disposiciones emitidas al comienzo del reinado, presentan una absoluta semejanza con aquéllas por lo que se refiere al aspecto territorial y no aportan en ello ninguna novedad (6), como tampoco la junta celebrada en Cigales donde se habla de modo general de «...todas las tierras e valles, e conçejos e cada vna de las dichas prouinçias...»; ahora bien, quedaron entonces convocadas para día cierto, uno de julio, juntas en ula cabeça de cada prouinçia» (7), siguiendo así lo preceptuado desde las ordenanzas fundacionales que indicaban que "...cada çibdad, o villa, o prouinçia, e valle, e merindad, o partido se junten cada vn año vna ves en la cabeça del tal partido a bos de Hermandad...». Sin duda, estas reuniones que habían de celebrarse en los diferentes distritos presuponían la creación de ámbitos que

(6) Cortes de 1476 IV, pet. 1, pp. 2-11.

(7) A. M. de Burgos LL. AA. 1476 fols. 37r-39r y A. M. de Toledo Arch. Secreto caj. 2. leg. 1, núm. 3 
lejos ya de las fórmulas antiguas se relacionaban concretamente con la organización de la Hermandad y garantizaban la consolidación de las relaciones que habian de establecerse entre las poblaciones de cada una de las demarcaciones, y entre éstas con el núcleo central.

Estas juntas provinciales en las que habían de tratarse cuantos asuntos tenían alguna vinculación con la provincia: empadronamientos y recaudaciones fiscales, disposición y movilización de los efectivos militares $y$, en general, todo lo referente a la administración de las materias competencia de la Hermandad (8), resultan un organismo de gran importancia en cuanto a la articulación de los diferentes ámbitos $y$, por otra parte, son complemento imprescindible de las Juntas generales (9), sirviendo además, en la etapa inicial como medio para llevar a efecto la adhesión de los lugares que anteriormente no hubieran ingresado en la Hermandad.

Aunque, dentro del esquema orgánico de la nueva corporación las Juntas provinciales tenían un papel específico en cuanto a la coordinación de las distintas comarcas y tierras dentro de la institución $y$, en este sentido, resultan un peldaño más en el marco del esfuerzo centralizador que la corporación hermandina representa, no son, sin embargo, totalmente ajenas a las tradiciones que hacían de estas reuniones el elemento integrador básico de los núcleos asociados por lo que una y otra vez aparecen en las cartas de hermandad como el lugar de contacto entre los asociados adecuado para la toma conjunta de decisiones.

Claro que la Junta provincial no es ahora un órgano decisorio sino un mecanismo de organización que permite llegar a todo el territorio y cohesionar a los lugares en el seno del nuevo marco institucional. De ahí que la convocatoria de estas reuniones sea de primaria importancia para la paulatina constitución de la organización provincial, cuyo proceso formativo fue tremendamente lento al principio siguiendo el rítmo del asentamiento y aceptación de la iniciativa regia en los diferentes rincones del reino.

El texto de las ordenanzas aprobadas en Dueñas en el verano de $1476(10)$ hace referencia explícita a ocho provincias, todas ellas situadas en torno al Duero, cuyos efectivos armados debían

(8) Como indicaban los ordenamientos de 1475 y de Cortes de 1476: «... para esecutar las penas e para entender e proueer en todas las cosas que vieren ser conplideras al buen estado de la dicha Hermandad....), sin salirse de las cuestiones de su competencia.

(9) En todas ellas se convocaban juntas provinciales para una fecha concreta: 1 de julio siguiente en la junta de Cigales; dia de Santa María de septiembre en la de Dueñas; 6 de enero en la de Santa María de Nieva; el día de la Trinidad en la siguiente de Dueñas; San Miguel de septiembre en la de Burgos; otra vez el día de la Trinidad en la junta celebrada en Pinto y Madrid, etc.

(10) A. M. de Toledo Arch. Secreto caj. 2, leg. 1, núm. 3; A. M. de Burgos LL. AA. 1476 fols. 50r-56r; A.G.S. Div. de Castilla leg. 8, núm. 2. 
reunirse en lugares preestablecidos, eran éstas: Palencia, Burgos, Segovia, Avila, Valladolid, León, Zamora y Salamanca, aunque su solidez era súmamente escasa e incluso las tres últimas demarcaciones no tenían preparadas sus gentes de armas ni la mecánica hacendística precisa para su sostenimiento (11). El dispositivo provincial sólo pudo irse formando en la medida en que se fueron venciendo las resistencias y generalizándose los ingresos en la entidad propuesta por la Corona. La Junta de Dueñas supuso un paso decisivo en el proceso de dotación institucional de la nueva Hermandad y en particular, por lo que se refiere al tema que nos ocupa porque en gran parte el esquema orgánico que se estaba diseñando reposaba sobre la organización territorial. En aquella oportunidad se dispuso el nombramiento de un diputado general permanente por provincia, cada una de las cuales nombraría asimismo un capitán y un escribano, al mismo tiempo, allí se habló de la creación en todos los distritos de un oficial en cuyas manos habría de descansar la acción ejecutiva del correspondiente distrito. En definitiva, en la obra constituyente que se lleva a cabo al paso de las asambleas celebradas en 1476 se fueron formando los esquemas básicos a los que responderán las nuevas provincias de modo que se pudo pasar en la práctica de las imprecisas nociones expuestas en las Cortes de Madrigal, donde los aspectos territoriales siguen las pautas de antaño, a unos distritos de nuevo cuño, en cierto modo artificiales si se quiere, pero adaptados a una institución planteada desde el poder central como palanca gubernativa del mismo.

El número de demarcaciones fue aumentando trabajosamente a lo largo del año siguiente; en la primavera de 1477 pudo darse forma a la provincia de Toledo, y en junio, los representantes de Puebla de Alcocer, Almadén, Chillón, Belalcázar, Siruela y otros procedían a nombrar un diputado general como provincia de Extremadura (12). En todo caso, en agosto, la junta celebrada en Burgos mencionaba expresamente un número de provincias más elevado: Burgos, León, Toledo, Segovia, Zamora, Palencia, Soria, Avila, Toro, Trujillo, Valladolid y, además, los territorios vascos de Guipúzcoa y Vitoria, de especiales características y con los que no volveremos a encontrarnos, de modo que, aparte de éstos, se sumaban Toledo y Trujillo al sur de las sierras del Sistema Central, y Toro, no contemplado anteriormente, en las inmediaciones del Duero (13).

(11) Todavía el 30 de agosto de 1477, A.G.S. R.G.S. fol. 502, los Reyes Católicos tenían que dirigirse a León y su provincia para que procedieran a organizar la Hermandad.

(12) A.G.S. Contaduría del Sueldo leg. 53, fol. 9

(13) A.M. de Toledo Arch. Secreto caj. 2, leg. 1, núm. 3. 
Desde el otoño de aquel año la corporación fue consolidándose en las regiones meridionales del reino (14), de manera que la siguiente junta general, celebrada al sur de los puertos, primero en Pinto y después en Madrid, para un más fácil acceso para los representantes de las regiones sureñas, pudo titularse ya como «junta general de dyputados e procuradores e mensajeros de las çibdades e villas e logares, seysmos e merindades destos reynos de Castilla e de León, de Toledo e del Andaluzian (15), en la que se aprobó la primera prórroga de la Hermandad por tres años.

En suma, a fines de la siguiente anualidad los reyes se dirigían a las provincias de la Hermandad para que durante el plazo de la prórroga vigente cumpliesen con las obligaciones correspondientes a su pertenencia a la entidad, indicando un mayor número de distritos, en los que se incluía ya la Andalucía Bética: Asturias de Oviedo, Burgos, Palencia, Valladolid, León, Zamora, Toro, Salamanca, Avila, Segovia, Soria, Madrid, Toledo, Guadalajara, Huete, Cuenca, Alcaraz, Murcia, Jaén, Córdoba, Sevilla, Trujillo y tierras del arzobispo de Toledo (16), aunque la realidad era por entonces algo más confusa y abundaban las comarcas extremeñas y andaluzas (17), pero también manchegas que o no habian procedido a efectuar su ingreso, o no pagaban las contribuciones a que estaban obligadas.

Naturalmente, el proceso de formación de la organización territorial es estrictamente paralelo al asentamiento de la Hermandad en los diferentes puntos del reino. Las dificultades de su aceptación en multitud de lugares, recuérdense como más característicos los casos de Sevilla o Toledo, por ejemplo, obligaron a un lento y paulatino proceso en el que tras ser impuesta la decisión regia de levantar la Hermandad en un ámbito determinado, ésta se organizaba en torno a las ciudades más destacadas por su significación política y económica, y también por su calidad de sede episcopal, como ocurrió en Andalucía -Sevilla, Córdoba y Jaén-o en Toledo, o bien, en función de demarcaciones señoriales de cierta coherencia geográfica y buena dimensión, como podrá observarse en las áreas de las órdenes militares de Santiago y Calatrava o en. las tierras del arzobispo de Toledo.

En los años ochenta y noventa la institución aparece estabilizada y. pasada la difícil etapa inicial que podríamos llamar constituyente,

(14) Por ejemplo, el 11 de octubre de 1477 se reunían en Alcaraz los procuradores de las poblaciones de esta provincia para celebrar junta que hubo de aplazarse por incomparecencia del capitán de la misma, PRETEL, A.: La integración de un municipio medieval en el estado autoritario de los Reyes Católicos (La ciudad de Alcaraz, 1475-1525), Albacete, 1979, p. 194.

(15) A.M. de Toledo Arch. Secreto caj. 2, leg. 1, núm. 3.

(16) 24 de diciembre de 1479, A.G.S. R.G.S. fol. 48.

(17) Tumbo de Sevilla, II, 17. 
funciona de manera regular. Lo propio ocurre por lo que se refiere a las provincias cuyos órganos actúan con normalidad, a salvo de alguna dificultad esporádica y de la siempre constante oposición contra el peso del fisco y, como no, contra la pérdida de peso específico de ciertas esferas de poder local y regional en aras de la centralización hermandina. Desde un punto de vista puramente descriptivo, hay que pensar que el número de las demarcaciones provinciales tiende también, lógicamente, a la estabilidad; sin embargo, no todas las listas que las fuentes documentales nos ofrecen coinciden exactamente (cuadro I). En cualquier caso y a la vista de dichas relaciones es posible ofrecer una serie que permita despejar las dudas suscitadas por tales diferencias. Sería la siguiente: Burgos, León, Asturias de Oviedo, Soria, Segovia, Avila; Salamanca, incluyendo las tierras del duque de Alba; Zamora, Toro, Valladolid, Palencia, Madrid, Guadalajara, Toledo, tierras del arzobispo de Toledo, provincia de Castilla de la Orden de Santiago, Huete, Cuenca, Alcaraz, Murcia, Jaén, Córdoba, Sevilla, Trujillo (18), y, por último, costas de la mar, Santander, Laredo y Trasmiera.

Todos los anteriores distritos aparecen, sin excepción, en el conjunto de los documentos considerados, pero además hay que incluir otros que en algún caso faltan, pero que de todos modos deberán ser añadidos a los anteriores, se trata de éstos: las tierras del condestable de Castilla y la provincia de León de la Orden de Santiago, que no sólo figuran siempre como demarcaciones específicas en cuanto al pago de la contribución ordinaria, sino que también disponian de juez ejecutor propio; tierras de la Orden de Calatrava, donde, del mismo modo, hubo juez ejecutor, y aparece además mencionada en las cuentas de gastos de malhechores de 1492/93; Orden de Alcántara, también con juez ejecutor; Ponferrada, incluyendo el ámbito señorial del marqués de Villafranca, distrito fiscal desde al menos 1490, considerado en las ya mencionadas cuentas de lo gastado en el seguimiento de delincuentes; finalmente, Ciudad Real, que con su pequeño alfoz estaba separada en lo fiscal y merece una especial consideración bien individualizada con respecto al inmediato Campo de Calatrava (19). Es decir, podemos registrar la existencia de 31 provincias, contando con Ciudad Real.

(18) Que en una ocasión se llama de Trujillo y Extremadura.

(19) LADERO QUESADA, M. A., op. cit., p: 109, ofrece la siguiente lista de provincias: Burgos; León; Soria; Palencia; Valladolid; Segovia; tierras de la Orden de Calatrava; del duque el Infantado; Provincia de Castilla de la Orden de Santiago; Huete; Trujillo. Sevilla con las costas de la mar de Andalucía; Ciudad Real; Santander, Laredo y tierras del condestable; Asturias de Oviedo, Ponferrada y tierras del marqués de Villafranca; Toro; Zamora; Avila; Toledo; tierras del arzobispo de Toledo; Córdoba; Jaén; Salamanca; Madrid; Guadalajara; Cuenca; Provincia de León de la Ordén de Santiago; Murcia y Alcaraz. 
En definitiva, son unidades territoriales, por lo general, sin relación concreta con otras formas antiguas de ordenación administrativa del espacio. En el valle del Duero, donde, como vimos, estaban las que se formaron al principio, surgen, a partir de un núcleo urbano de mayor relevancia regional en torno al cual se agrupan las comarcas cercanas, tanto las que tenían vinculaciones jurisdiccionales con la urbe como otras que no presentaban relación alguna de este orden.

No hay coincidencia con las diócesis episcopales, piénsese que si muchas de las ciudades que gozaron de la capitalidad provincial en esta zona fueron sede también de catedrales, otras no, como, por ejemplo, Toro o Ponferrada, $y$, en cambio, Astorga o Ciudad Rodrigo, que contaban con obispo, dependían a los efectos hermandinos de otras cabeceras. Por tanto, se trata de distritos en cierto modo artificiales $y$ de naturaleza específicamente funcional que, de todos modos, venían a reconocer y seguir la influencia de ciertos polos que actuaban como puntos de centralidad regional en virtud de su relieve en los terrenos económico, demográfico, etc., algunos de los cuales obtenían así un ascenso político al carecer de voto en Cortes -recordemos el caso de Palencia, entre otros.

Al sur de los puertos del sistema montañoso central, encontramos una novedad: la aparición como demarcaciones hermandinas de varias áreas señoriales pertenecientes a las órdenes militares -Santiago, Calatrava, Alcántara- y al arzobispo toledano. La extensión y carácter compacto de estos territorios, así como la carencia en las llanuras de núcleos de alguna importancia, generan la aparición de estas provincias, que responden con coherencia a la forma de ocupación administrativa y jurisdiccional de la tierra procedente de la época de la repoblación. Lógicamente, al norte de Extremadura y Castilla la Nueva diferentes condicionamientos hacen que las provincias de Trujillo, Toledo, Madrid, Guadalajara, Huete y Cuenca respondan a otras características más semejantes a las observadas en el Duero al ordenarse en torno a las ciudades; en tanto que al sureste el núcleo murciano articula aquella región desde la costa hasta Albacete, dejando espacio lateralmente para la pequeña demarcación dirigida desde Alcaraz (20).

Con respecto a Andalucía, se forman tres provincias, encabezadas por Jaén, Córdoba y Sevilla, todas ellas sedes episcopales,

(20) Aunque hubo presiones de la corona para que Alcaraz se sumara a Murcia, ingresó en la Hermandad en 1477 integrando una provincia formada por su término y la mayor parte de las villas de Montiel: Villanueva del Infante, Villahermosa, Fuenllana; Torre de Juan Abad, Villamanrique, Alhambra, La Solana, Terrinches y Membrilla, PETREL, A., op. cit., p. 192. En la provincia de Murcia encontramos las siguientes localidades: Murcia, Lorca, Ceutí, Lorquí, Albudeite, Cotillas, Lebrilla, Molina, Cartagena, Chinchilla, Albacete, Almansa, Hellín, Villena, Sax, Montealegre, Ves, Tobarra, Yecla, Abanilla, ABELLÁN, J. M. ${ }^{a}$, op. cit., pp. 34-36. 
aunque Cádiz, que también lo era, hubo de sumarse a esta última, que adquirió una importante dimensión en el cuadrante suroeste del reino castellano hasta la raya de Portugal.

La organización institucional de las provincias comenzó a formarse ya en la primera etapa del desarrollo de la Hermandad, pero no se trataba ahora de dar forma orgánica a las hermandades. ciudadanas y territoriales agregadas en un cuerpo que se apoyase en ellas, sino que, en sentido contrario, la nueva corporación, fuertemente centralizada en todos los aspectos $y$, en particular, en cuanto a su gestión (21), apenas delegó poderes decisorios a los distritos que iban consolidándose, entendiéndolos como simple medio de ordenación del espacio, de modo que se facilitase la labor centralizadora y las medidas adoptadas en la cumbre pudiesen alcanzar los más alejados confines del reino. Por consiguiente, el esquema organizativo puesto en práctica hacia que los escalones inferiores dependiesen fuertemente de los superiores -es decir, los pueblos con respecto a los centros provinciales y éstos, a su vez, con respecto a los órganos superiores.

$Y$ así puede verse si se estudia el proceso de constitución de las instituciones territoriales. La primera de ellas, las juntas de cada partido o demarcación, entendidas de un modo no muy alejado de la tradición en los ordenamientos findacionales, tanto en el inicial de 1475 como en el de Cortes de 1476, se transformáron pronto, ya en Cigales en junio de aquel mismo año, en mecanismos de adhesión de las poblaciones a la Hermandad y de presentación de los padrones e informaciones precisas para la puesta en marcha de los objetivos de la corporación, en total dependencia de las decisiones tomadas previamente por la Corona y sus representantes, y aunque en Dueñas, en agosto de 1476, se dijera de estas reuniones en un tono muy general: «... a donde se probea en las otras cosas que ocurrieren que fueren nesçesarias...», en realidad, su autonomía será escasa, quedando como elemento básicamente informativo y no decisorio (22), de suerte que el número de los representantes que acudian a las convocatorias parece que fue reduciéndose.

Con independencia de estas juntas que, como sabemos, fueron haciéndose regularmente a lo largo de todo el período de vigencia de la Hermandad, en el mismo ordenamiento aprobado en Dueñas, y que inmediatamente antes recordábamos, se dispuso el nombramiento de un capitán por provincia y también un escribano para que trabajase en los diferentes asuntos hermandinos en el distrito con

(21) Sobre los órganos centrales de la Hermandad, ver LUNENFELD, M., op. cit.

(22) Aunque su control no dejase de ser importante, como apunta LUNENFELD, op. cit., pp. 64-65, para garantizar que actuasen de acuerdo con la política regia. 
obligación de acudir a las juntas generales (23). Posteriormente, en agosto de 1477, las ordenanzas de Burgos, regulaban el oficio de juez ejecutor, el que habrá de ser el principal cargo de cada distrito. En el ordenamiento se habla textualmente de «...vna presona fiable de prudençia e de conçiençia que touiese cargo de toda la dicha prouinçia en todas las cosas a ella pertenesçientes en que buenamente el diputado general non podria entender e por estar absente e por resydir en la dyputaçion e por los cargos ser grandes...ly. Sus funciones consistían básicamente en acudir a las juntas tanto generales como provinciales, ocuparse de requerir y movilizar los efectivos armados y medios para sostenerlos, poner orden en el personal de la Hermandad, etc., por ello, estas personas aparecen en la documentación interviniendo en los más diversos temas relativos a la dirección superior de su demarcación (24). Eran nombrados por los monarcas (25), dándose en alguna ocasión el caso de hereditariedad en el oficio -así ocurrió en Palencia cuando Alonso González de Palencia sucedió a su padre fallecido, el doctor Fernán González de Palencia (26) - y podían ser sometidos a residencia: el corregidor de Avila lo hizo con Diego de Gamarra en aquella provincia en 1488 (27). Por lo que se refiere a la duración de su mandato no existía plazo concreto y algunos permanecieron largo tiempo en el mismo como, por ejemplo, el doctor del Espinar o el licenciado de Illescas, en Segovia y Valladolid, respectivamente, que designados en 1477 todavía permanecían a comienzos de los años noventa encargados de esta responsabilidad.

(23) Una provisión real nombrando escribano de la Hermandad en la provincia de Madrid en A.M. de Madrid Libro Horadado fol. 372r-v.

(24) Gonzalo de Bonilla, juez ejecutor en Sevilla tuvo enfrentamientos con los alcaldes de hermandad de la ciudad porque se entrometía en las causas penales a ellos pertenecientes, 29 de noviembre de 1486. Tumbo de Sevilla III, 133.

(25) En el propio ordenamiento de Burgos se designan ya los jueces ejecutores de varias provincias: el licenciado del Castillo en.Burgos; el licenciado de tordehumos en León; el jurado Alvar García de Toledo en Toledo; el doctor del Espinar en Segovia; el bachiller Diego Pérez en Zamora; el bachiller de Dueñas en Palencia; el bachiller Juan de Avila en Avila; Fernando de Vadillo en Toro; el bachiller Juan Romero en Trujillo; el licenciado de lllescas en Valladolid, y también otras dos personas correspondientes a Guipúzcoa y Vitoria, precisando que los diputados y procuradores presentes en la junta se lo notificasen para que «non pretendan ynorançia que lo non sopieron e fueles mandado que açepten los dichos cargos e fagan lo que asy les es mandado so pena de cada çinquenta mill mrs. para las dichas hermandades en que les condepnaron e ovieron por condepnados sy lo non conplieren». En 1485, por ejemplo, los reyes ordenaban a los concejos correspondientes que obedeciesen a García Alvarez de Amusco como juez ejecutor en el maestrazgo de Alcántara 5 de marzo de 1485, A.G.S. R.G.S. fol. 163. Los soberanos, por otra parte, encargaron a Gonzalo de Bonilla que ocupase el cargo en Sevilla durante la ausencia del comendador Pedro de Cervantes, 13 de abril de 1483, Tumbo de Sevilla II, 217, cuatro años más tarde al retornar éste que había estado preso en poder de los musulmanes le fue devuelto el puesto, 20 de agosto de 1487, A.G.S. R.G.S. fol. 32326 y Tumbo de Sevilla III, 186.

(26). Durante su minoridad se encargó interinamente de la responsabilidad su tío Francisco González de Sevilla.

(27) 15 de noviembre de 1488, A.G.S. R.G.S., fol. 102. 
Por lo demás, en las poblaciones actuaban alcaldes y cuadrilleros que componian una extensa red dedicada específicamente a las tareas de seguridad y justicia, à través de los cuales la presencia de la acción hermandina llegaba a los lugares y rincones más alejados (28), $y$, por otra parte, las provincias estaban representadas en el Consejo de la Hermandad mediante los diputados generales, uno por cada circunscripción, elegidos primero por cuatro meses y luego por seis, aunque en realidad, los órganos centrales de la institución fueron siempre instrumento directo del poder real (29).

Desde otro punto de vista, las provincias aparecen también como marco territorial para la recaudación de la contribución ordinaria mediante la cual se sostenían económicamente los distintos mecanismos del edificio hermandino. Como es sabido, a través de ella se obtuvieron $17.800 .000 \mathrm{mrs}$. anuales entre 1478 y 1485 , y entre 32.000 .000 y $34.500 .000 \mathrm{mrs}$. desde este año hasta la terminación de estas actividades fiscales en 1498 (30). Resultó pues, un medio indudablemente productivo de captación de recursos (31), sin olvidar los que se movilizaron con carácter extraordinario, de tanta utilidad durante los años de la guerra de Granada (32).

Dejando a un lado estos últimos, la contribución ordinaria que en cada punto podía cobrarse de manera directa, por repartimiento, o bien, mediante impuestos indirectos, sisas, o de los propios de cada concejo, según se estableció desde el primer momento, ya en Cortes de 1476; se enviaba en los plazos previamente previstos desde cada población a la capital de la provincia (33) donde se procedía al registro de las cantidades remitidas que quedaban a disposición de la institución (34).

(28) No trataremos en este trabajo sobre las funciones de persecución de malhechores. Cabe recordar de todos modos que en este aspecto se sigue el modelo iniciado por la Hermandad Vieja de Toledo, Talavera y Ciudad Real, que he estudiado en mi trabajo Santa Hermandad Vieja de Toledo. Talavera y Ciudad Real (siglos XIII-XV). Toledo, 1987.

(29) Como señala LUNENFELD,op. cit., p. 102; el Consejo de la Hermandad es leal a la corona y no a las ciudades.

(30) LAREDO QUESADA, M. A.: La hacienda real de Castilla en el siglo XV. La Laguna, 1973, pp. 214-15, y La hacienda real de Castilla en 1504. Rentas y gastos de la Corona al morir Isabel I, H. ${ }^{a}$, Inst.; Docs. III, 1976, p. 315. También LUNENFELD, M.: Op. cit., pp. 68-69.

(31) Como cree LUNENFELD, op. cit., p. 74.

(32) Ladero ha establecido que por esta vía se ingresaron 261,5 millones de mrs., La hacienda real de Castilla en $1504 \ldots$, cit., p. 315.

(33) SÁNCHEZ BENITO, José María: La financiación de la Hermandad de los Reves Católicos en la provincia de Cuenca, Cuenca, Rey. de la Excma. Diputación Provincial de Cuenca len prensa).

(34) Los libros de actas del concejo de Madrid; por ejemplo, muestran los testimonios de la presentación de las correspondientes cartas de receptoría expedidas por los tesoreros de la Hermandad, C. Rubio Pardos, T. Moreno Valcárcel, C. de la Fuente Cobos, E. Meneses García, Libro de acuerdos del concejo madrileño, III, 1493-97, pp. 34, 168, 256, todos ellos referentes a esta provincia. Cuentas de lo ingresado por esta contribución en la provincia de Cuenca, en

REVISTA DE ESTUDIOS. -12 
Desde la junta de Burgos de 1477 los máximos responsables provinciales quedaban facultados para en las asambleas de la demarcación demandar cuenta de los pagos efectuados por los diferentes lugares. En estas mismas juntas se informaba sobre lo que debía abonarse $y$, lógicamente, a ellas podían llegar quejas $y$ discrepancias de los pueblos, aunque a estas reuniones las más de las veces no acudían los núcleos poblados más pequeños y se celebraban con bien escasa asistencia (35).

Las provincias, de tamaño, población y capacidad productiva bien diferentes pagaban cada año, por lo que se refiere a la contribución ordinaria, sumas bastante regulares que sólo se vieron sometidas a sensible variación en torno a 1485-86. Estas cantidades cobradas en cada uno de los distritos son índice en primer lugar de las posibilidades de pago al fisco de cada territorio, pero eso, a su vez, manifiesta su peso específico y de un modo indirecto su demografía, recursos y producción, de ahí que presente interés recoger tales cifras, aunque sean sólo de cuatro anualidades: $1488-89,1490-91,1491-92$ y 1492-93 (cuadro IV).

Si bien es cierto que muchos ámbitos señoriales pagaron esta imposición mediante un tanto alzado, las demarcaciones provinciales fueron el marco para la percepción de la contribución ordinaria desempeñando una vez más un papel de mera ordenación del espacio en la aplicación de los mandatos centrales, pero sin capacidad decisoria alguna.

Es verdad que la palabra provincia no era en el último cuarto del siglo XV ninguna novedad, había sido utilizada con anterioridad e incluso en medios de las anteriores hermandades, sin embargo, en la entidad suscitada por los Reyes Católicos este término llegó a llenarse plenamente de contenido y a alcanzar una importancia en orden a la administración del país castellano que sí es seguramente novedad. Como se ha indicado antes se observa un cambio

A. M. de Cuenca, leg. 1477, exp. 1, 2 y 3, y leg. 1478, exp. 1 y 2; con respecto a Toledo, A. M. de Toledo, Arch. Secreto, caj. 2, leg. 1, núm. 7.

(35) Un texto de 1488, relativo al repartimiento extraordinario aprobado en la junta de Aranda, A.G.S., Contaduría del Sueldo, $1 .^{\mathrm{a}}$ serie, leg. 53, fol. 5, viene a clarificar esto, por lo que reproducimos a continuación: "A paresçido a algunos que a sus altezas plazeria que ouisse juntas prouinçiales y que de aqui o de la cabeça de la prouinçia se hiziese saber cada conçejo lo que ha de pagar, lo qual aca mucho platicado hallase ser cosa de grand ynconveniente porque de las prouinçias sy ay en cada prouinçia quinientos lugares non vienen a la junta general treynta procuradores y a ver de enbiar a cada concejo de aqui seria grand costa y quando fuese acabado de fazerlo saber a cada conçejo seria pasada la mytad del tienpo en han de conplir. $Y$ tanbien porque en las juntas prouinçiales se lee el repartymiento oreginal y ven todos lo que les cabe, e los vnos a los otros conoçen sy les hazen agrauio o syn razon, y sy veen que van yguales van satysfechos, otra manera avrian sospecha que les hazian algund agrauio, y por esto y por otras cosas que serian largas de escreuir las juntas prouinçiales non se deuen descansar sy a sus altezas non plaze mandar otra cosa, y que se deuen de hazer en todo el mes de hebrero porque alli sepan todos lo que han de pagar e a que plazos...» 
sustancial entre las previsiones contempladas en los ordenamientos iniciales, no muy alejados de lo tradicional, y la estructura territorial que aparece funcionando regularmente en los años ochenta y noventa hasta 1498 , produciéndose un distanciamiento respecto de la herencia recibida de las anteriores experiencias hermandinas en aras de una progresiva centralización que hace de las provincias, tal como estas fueron utilizadas en estos tiempos, unos ámbitos geográfico-administrativos en los cuales se agruparon áreas dependientes de diferentes jurisdicciones y que posibilitaron la puesta en práctica de las decisiones centrales y la organización del espacio imprescindible para ello durante el limitado perído de vigencia de los órganos y mecanismos militares, fiscales, etc., de la Hermandad, desaparecidos, como es bien sabido, en 1498 (36).

Piénsese, por último, que tales mecanismos se referían a facetas fundamentales del ejercicio del poder en la época por lo cual la organización provincial aunque sólo tenga relación con lo concerniente a la Hermandad alcanza un valor considerable, en tiempos de indiscutible crecimiento de la influencia de la Monarquía, como fórmula de encuadramiento administrativo, fiscal y militar principalmente, y si bien su período de duración es relativamente corto, poco más de veinte años, representa una etapa en la maduración y racionalización de las formas de ejercer el poder regio $y$, en particular, de la ordenación del espacio para ello necesaria, que de ningún modo debe olvidarse.

CUADRO I

\section{Las provincias}

\begin{tabular}{l|l|l|l}
\hline $\begin{array}{c}\text { Lista de provincias } \\
\text { procedente de la relación } \\
\text { de cantidades } \\
\text { a ingresar } \\
\text { mediante contribución } \\
\text { ordinaria } \\
\text { en } 1488-89(37)\end{array}$ & $\begin{array}{c}\text { Lista de provincias } \\
\text { procedentes de la relación } \\
\text { de cantidades } \\
\text { ingresadas } \\
\text { en } 1490-91, \\
1491-92 \text { y } 1492-93 \\
(38)\end{array}$ & $\begin{array}{c}\text { Lista procedente } \\
\text { de las cuentas } \\
\text { de gastos } \\
\text { en la persecución } \\
\text { de malhechores } \\
1490-91,1491-92, \\
\text { y } 1492-93(39)\end{array}$ & $\begin{array}{c}\text { Lista procedente } \\
\text { de la relación } \\
\text { de jueces ejecutores } \\
\text { provinciales } \\
\text { pagados con cargo } \\
\text { a la contribución } \\
\text { de } 1489(40)\end{array}$ \\
\hline $\begin{array}{c}\text { Burgos. } \\
\begin{array}{c}\text { León. } \\
\text { Tierras del Condes- } \\
\text { table. }\end{array}\end{array}$ & $\begin{array}{l}\text { Burgos (41). } \\
\text { León. } \\
\text { Tierras del Con- } \\
\text { destable. }\end{array}$ & $\begin{array}{l}\text { Burgos. } \\
\text { León. }\end{array}$ & $\begin{array}{l}\text { Burgos. } \\
\text { León. } \\
\text { Tierras del Condes- } \\
\text { table. }\end{array}$
\end{tabular}

(36) La pragmática de 29 de julio de 1498 eliminó la contribución y la totalidad de los organismos de la Hermandad, con excepción de alcaldes y cuadrilleros, Libro de bulas y pragmáticas de los Reyes Católicos, ed. A. García Gallo, Madrid, 1973, fols. 177r-180r.

(37) A.G.S. Contaduría del Suelo, 1. ${ }^{a}$ serie, leg. 53, fol, 2.

(38) A.G.S. Contaduría Mayor de Cuentas, 1. ápoca, leg, 134.

(39) Ibidem.

(40) A.G.S. Contaduría del Suelo, $1 .^{a}$ serie, leg. 53, fol. 15.

(41) Figura aparte la ciudad. 


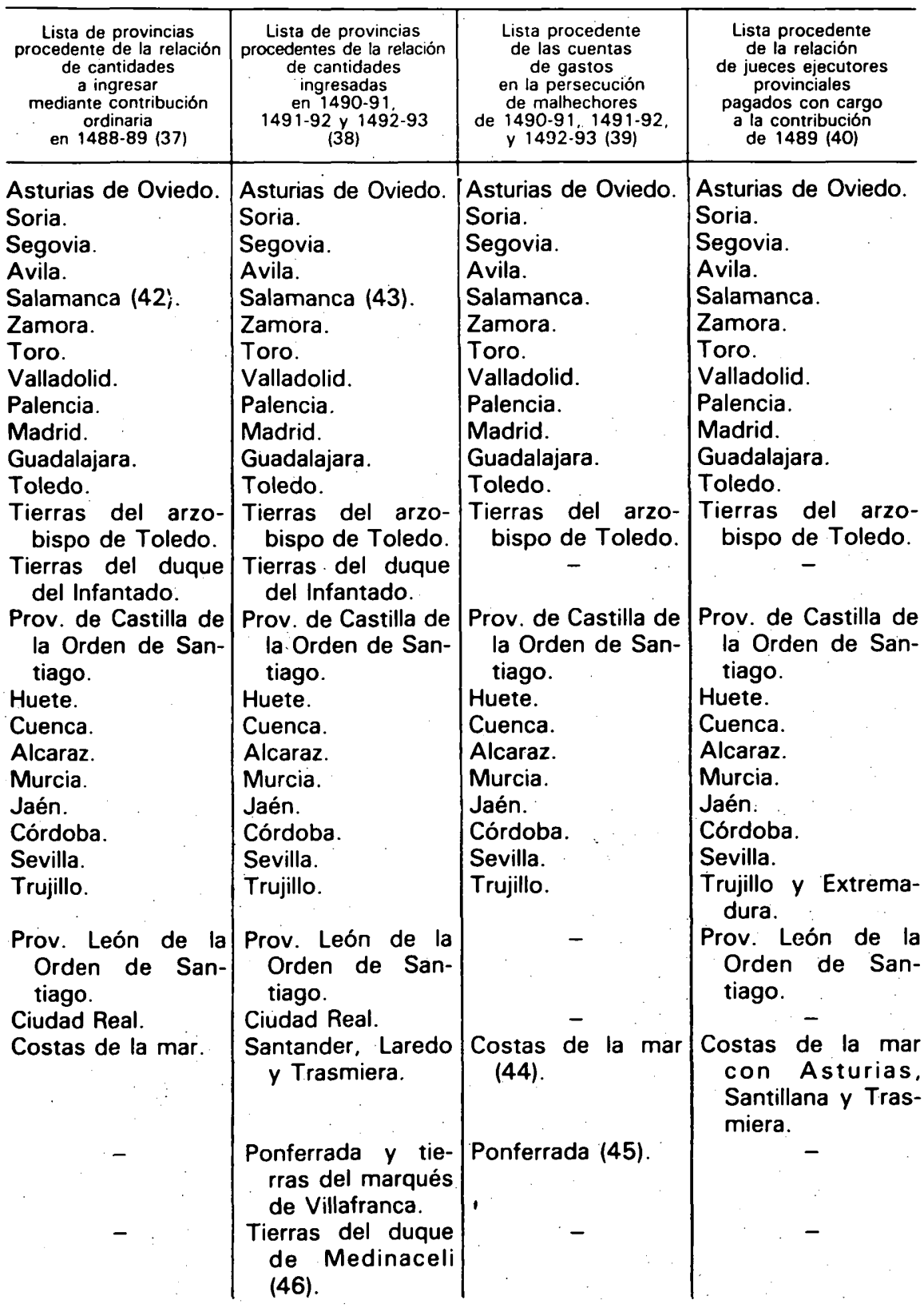

(42) Junto con las tierras del duque de Alba.

(43) Id.

(44) Sólo en 1492/93.

(45) Sólo en 1492/93.

(46) Sólo en 1491/92 y 1492/93. 


\begin{tabular}{|c|c|c|c|}
\hline $\begin{array}{l}\text { Lista de provincias } \\
\text { procedente de la relación } \\
\text { de cantidades } \\
\text { a ingresar } \\
\text { mediante contribución } \\
\text { ordinaria } \\
\text { en } 1488-89 \text { (37) }\end{array}$ & $\begin{array}{c}\text { Lista de provincias } \\
\text { procedentes de la relación } \\
\text { de cantidades } \\
\text { ingresadas } \\
\text { en } 1490-91 \\
1491-92 \text { y } 1492-93 \\
\text { (38) }\end{array}$ & $\begin{array}{c}\text { Lista procedente } \\
\text { de las cuentas } \\
\text { de gastos } \\
\text { en la persecución } \\
\text { de malhechores } \\
\text { de } 1490-91,1491-92 \text {. } \\
\text { y } 1492-93 \text { (39) }\end{array}$ & $\begin{array}{c}\text { Lista procedente } \\
\text { de la relación } \\
\text { de jueces ejecutores } \\
\text { provinciales } \\
\text { pagados con cargo } \\
\text { a la contribución } \\
\text { de } 1489(40)\end{array}$ \\
\hline $\begin{array}{l}- \\
-\end{array}$ & . & $\begin{array}{l}\text { Tierras de la Orden } \\
\text { de Calatrava } \\
\text { (47). } \\
\quad\end{array}$ & $\begin{array}{l}\text { Tierras de la } 0 . \\
\text { Calatrava. } \\
\text { Tierras de la Orden } \\
\text { de Alcántara. }\end{array}$ \\
\hline
\end{tabular}

CUADRO ॥

Núcleos de población de las provincias de Cuenca, Toledo y Sevilla

\begin{tabular}{|c|c|c|}
\hline Cuenca & Toledo & Sevilla \\
\hline $\begin{array}{l}\text { Arcos de la Sierra. } \\
\text { Albalate. } \\
\text { Arrancacepas. } \\
\text { Arcos de la Cantera. } \\
\text { Arcas. } \\
\text { Altarejos. } \\
\text { Algar. } \\
\text { Albadalejo. } \\
\text { Abia. } \\
\text { Alarcón. } \\
\text { Alcalá. } \\
\text { Alberca. } \\
\text { Alcantud. } \\
\text { Almodóvar. } \\
\text { Buenache de la Sierra. } \\
\text { Bolliga. } \\
\text { Belmontejo. } \\
\text { Buenache de Alarcón. } \\
\text { Barchin. } \\
\text { Beamud. } \\
\text { Barbalimpia. } \\
\text { Bascuñana. } \\
\text { Castillejo. } \\
\text { Collados. } \\
\text { Castillejo de Alvarchantes. } \\
\text { Chillarón. } \\
\text { Cabrejas. } \\
\text { Colliguilla. } \\
\text { Campillo. } \\
\text { Chumillas. }\end{array}$ & $\begin{array}{l}\text { Toledo, montes y pro- } \\
\text { pios. } \\
\text { Alcázar de Consuegra. } \\
\text { Consuegra. } \\
\text { Madridejos. } \\
\text { Urda. } \\
\text { Tembleque. } \\
\text { Yébenes. } \\
\text { Quero. } \\
\text { Camuñas. } \\
\text { Villacañas. } \\
\text { Arenas. } \\
\text { Villafranca. } \\
\text { Villaharta. } \\
\text { Cedillo. } \\
\text { Erencia. } \\
\text { Huerta. } \\
\text { Pero Moro. } \\
\text { Humanes. } \\
\text { Guardamur. } \\
\text { Fuensalida. } \\
\text { Villaseca. } \\
\text { Cebolla. } \\
\text { Santa Olaya. } \\
\text { Villaluenga. } \\
\text { Ajofrín. } \\
\text { Villacarrillo. } \\
\text { Layos. } \\
\text { Barciente. } \\
\text { Carranque. } \\
\text { Viso. } \\
\text { Pinto. }\end{array}$ & $\begin{array}{l}\text { Sevilla y su tierra. } \\
\text { Jerez de la Frontera. } \\
\text { Ecija. } \\
\text { Umbrete. } \\
\text { Rianzuela. } \\
\text { Villalba. } \\
\text { Lora. } \\
\text { Carmona. } \\
\text { Palma. } \\
\text { Serrezuela. } \\
\text { Alcalá de Juana Dorta. } \\
\text { Castillejón de Talhara. } \\
\text { Robaina. } \\
\text { Tosina. } \\
\text { Castillejón de Alcántara. } \\
\text { Albaida. } \\
\text { Heliche. } \\
\text { Olivares. } \\
\text { Gines. } \\
\text { Chucena. } \\
\text { Gandul. } \\
\text { Marchenilla. } \\
\text { Gelves. } \\
\text { Carrión. } \\
\text { Viso. } \\
\text { Alcolea. } \\
\text { Gatos. } \\
\text { Fuentes. } \\
\text { Guadajoz. } \\
\text { Benazón. } \\
\text { Cantillana. }\end{array}$ \\
\hline
\end{tabular}

(47) Sólo en 1492/93. 
REVISTA DE ESTUDIOS DE LA ADMINISTRACION LOCAL Y AUTONOMICA

\begin{tabular}{|c|c|c|}
\hline Cuenca & Toledo & Sevilla \\
\hline $\begin{array}{l}\text { Cañada. } \\
\text { Cañete. } \\
\text { Cañaveras. } \\
\text { Cañabate. } \\
\text { Cerecedo. } \\
\text { Castillo. } \\
\text { Cañizares. } \\
\text { Cólliga. } \\
\text { Enguídanos. } \\
\text { Embid. } \\
\text { Embid. } \\
\text { Fresneda. } \\
\text { Fresneda de Altarejos. } \\
\text { Fuenteherruz. } \\
\text { Fuentesclaras. } \\
\text { Fuentes. } \\
\text { Frontera. } \\
\text { Fuentescusa. } \\
\text { Gabaldón. } \\
\text { Hontecillas. } \\
\text { Huerta. } \\
\text { Honrubia. } \\
\text { Hinojosa. } \\
\text { Hinojosos. } \\
\text { Iniesta. } \\
\text { Jábaga. } \\
\text { Jumilla. } \\
\text { Mariana. } \\
\text { Mohorte. } \\
\text { Melgosa. } \\
\text { Motilla. } \\
\text { Monteagudo. } \\
\text { Majadas. } \\
\text { Mantiel. } \\
\text { Minaya. } \\
\text { Monreal. } \\
\text { Montalbanejo. } \\
\text { Mochales. } \\
\text { Mesas. } \\
\text { Mira. } \\
\text { Mota. } \\
\text { Moya. } \\
\text { Navalón. } \\
\text { Noheda. } \\
\text { Olmeda. } \\
\text { Olmeda de la Cuesta. } \\
\text { Olmedilla. } \\
\text { Ocentejo. } \\
\text { Osa. } \\
\text { Olivares. } \\
\end{array}$ & $\begin{array}{l}\text { San Silvestre. } \\
\text { Orgaz. } \\
\text { Gálvez. } \\
\text { Jumela. } \\
\text { Malpica con S. Martín. } \\
\text { Batres. } \\
\text { Puebla de Guadalupe. } \\
\text { Mejorada. } \\
\text { Cervera. } \\
\text { Puebla de Montalbán. } \\
\text { Azután. } \\
\text { Cobilla. } \\
\text { Escalona. } \\
\text { Villanueva. }\end{array}$ & $\begin{array}{l}\text { Santiponce. } \\
\text { Algaba. } \\
\text { Brenes. } \\
\text { Villaverde. } \\
\text { Cádiz. } \\
\text { Sta. María del Puerto. } \\
\text { Moguer. } \\
\text { Palos. } \\
\text { Lepe. } \\
\text { Ayamonte. } \\
\text { Redondela. } \\
\text { Gibraleón. } \\
\text { Cartaya. } \\
\text { S. Miguel de Arca de } \\
\text { Buey. } \\
\text { Almonaster. } \\
\text { Zalamea. } \\
\text { Villanueva del Fresno. } \\
\text { Antequera. } \\
\text { Teba. } \\
\text { Carretejo la Real. } \\
\text { Torre Alhaquín. } \\
\text { Los Molares. } \\
\text { Coronil. } \\
\text { Morón. } \\
\text { Arahal. } \\
\text { Osuna. } \\
\text { Archidona } \\
\text { Olvera. } \\
\text { Alcalá de los Gazules. } \\
\text { Bornos. } \\
\text { Espera. } \\
\text { Castellar. } \\
\text { Arcos. } \\
\text { Zara. }\end{array}$ \\
\hline
\end{tabular}


CRONICAS

\begin{tabular}{|c|c|c|}
\hline Cuenca & Toledo & Sevilla \\
\hline 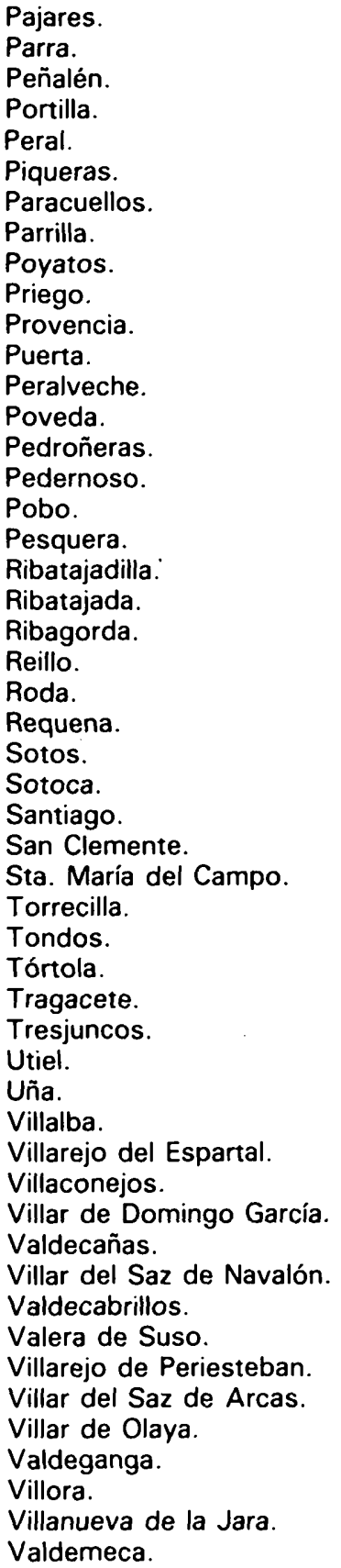 & & \\
\hline
\end{tabular}



REVISTA DE ESTUDIOS DE LA ADMINISTRACION LOCAL Y AUTONOMICA

\begin{tabular}{|c|c|c|}
\hline Cuenca & Toledo & Sevilla \\
\hline $\begin{array}{l}\text { Valdecabras. } \\
\text { Valverde. } \\
\text { Vara de Rey. } \\
\text { Villarejo Seco. } \\
\text { Villarejo sobre Huerta. } \\
\text { Valera de Yuso. } \\
\text { Yunta. } \\
\text { Zarzuela. } \\
\text { Zafra. }\end{array}$ & & \\
\hline
\end{tabular}

CUADRO III

Relación de jueces ejecutores en torno a 1490

\begin{tabular}{|c|c|}
\hline 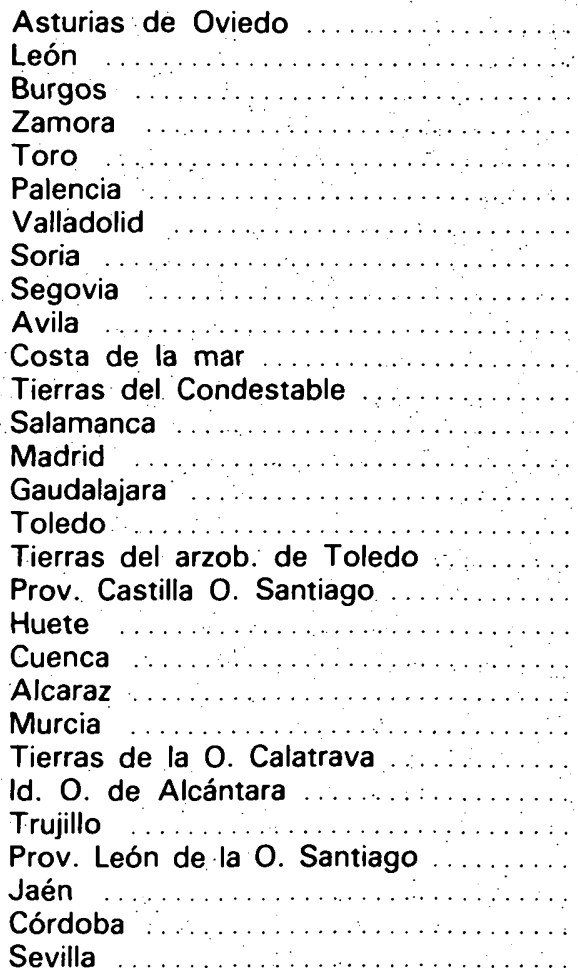 & $\begin{array}{l}\text { Pedro de Avila (48). } \\
\text { Pedro del Campo. } \\
\text { Licenciado del Castillo. } \\
\text { Diego Pérez. } \\
\text { Fernando de Sotelo. } \\
\text { Dr. de Palencia. } \\
\text { Licenciado de llescas. } \\
\text { Licenciado Andrés Caiderón. } \\
\text { Dr. del Espinar. } \\
\text { Gil de Aguila. } \\
\text { Juan de Salablanca. } \\
\text { Diego de Medina. } \\
\text { Juan de Villafuerte. } \\
\text { Dr. de Madrid. } \\
\text { Pedro Gómez de Ciudad Real. } \\
\text { Juan Niño. } \\
\text { Juan de Barrionuevo. } \\
\text { Lope Alvarez Osorio. } \\
\text { Esteban Cuello. } \\
\text { Pedro Suárez de Alcalá. } \\
\text { Licenciado de Balvas. } \\
\text { Licenciado de Belmonte. } \\
\text { Rodrigo Bermúdez. } \\
\text { García Alvarez de Amusco. } \\
\text { Pedro de Jarada. } \\
\text { Rodrigo de Cárdenas. } \\
\text { Pernando Mexía. } \\
\text { Alfonso de Angulo. } \\
\text { Pedro de Cervantes. }\end{array}$ \\
\hline
\end{tabular}

(48) Corregidor del principado. 
CUADRO IV

Cantidades pagadas por las provincias en la contribución ordinaria

\begin{tabular}{|c|c|c|c|c|}
\hline$\therefore$ & $\begin{array}{c}1488 / 89 \\
(49)\end{array}$ & $\begin{array}{c}1490 / 91 \\
(50)\end{array}$ & $1491 / 92$ & $1492 / 93$ \\
\hline $\begin{array}{l}\text { Burgos. } \\
\text { Asturias. } \ldots \ldots \ldots \\
\text { León } \ldots \ldots \ldots \\
\text { Tierras Condestable } \ldots \ldots \ldots \\
\text { Ponferrada } \quad \ldots \ldots \ldots \ldots \ldots \ldots\end{array}$ & $\begin{array}{r}2.449 .760 \\
200.000 \\
1.699 .320 \\
208.100\end{array}$ & $\begin{array}{r}2.345 .320 \\
200.000 \\
1.465 .240 \\
208.100 \\
141.254 \\
(51)\end{array}$ & $\begin{array}{r}2.383 .320 \\
200.000 \\
1.462 .060 \\
208.101 \\
221.254\end{array}$ & $\begin{array}{r}2.413 .260 \\
200.000 \\
1.451 .780 \\
208.101 \\
220.594\end{array}$ \\
\hline Zamora : & 999.160 & 993.660 & 994.140 & 994.140 \\
\hline $\begin{array}{l}\text { Toro } \ldots \ldots \\
\text { Soria } \ldots \ldots\end{array}$ & $\begin{array}{r}582.520 \\
1.322 .450\end{array}$ & $\begin{array}{r}560.530 \\
1.314 .450\end{array}$ & $\begin{array}{r}560.530 \\
1.314 .450\end{array}$ & $\begin{array}{r}560.530 \\
1.314 .450\end{array}$ \\
\hline Segovia $\ldots$ & 1.901 .000 & 1.901 .000 & 1.901 .000 & 1.901 .000 \\
\hline Avila $\quad \therefore \ldots$ & 1.263 .300 & 1.262 .500 & 1.262 .500 & 1.262 .500 \\
\hline Salamanca & 1.746 .050 & 1.761 .660 & 1.761 .660 & 1.761 .660 \\
\hline Valladolid & 1.624 .820 & 1.611 .240 & 1.604 .160 & 1.600 .560 \\
\hline Palencia & 1.744 .205 & 1.741 .780 & 1.731 .485 & 1.717 .040 \\
\hline Madrid & 640.415 & 472.315 & 634.275 & 633.135 \\
\hline Toledo & 1.542 .460 & 1.173 .820 & 1.173 .820 & 1.173 .120 \\
\hline Tierras arzob. Toledo & 540.000 & 540.000 & 557.640 & 557.640 \\
\hline Guadalajara...$\ldots \ldots$ & 681.060 & & $\begin{array}{c}943.960 \\
(52)\end{array}$ & \\
\hline Tierras duque Infantado .... & 288.480 & .960 & 288.480 & .170 \\
\hline $\begin{array}{l}\text { Prov. Castilla Orden Santiago } \\
\text { Huete } \ldots \ldots \ldots \ldots \ldots \ldots \ldots\end{array}$ & $\begin{array}{l}568.160 \\
501.060\end{array}$ & $\begin{array}{l}578.160 \\
510.960\end{array}$ & $\begin{array}{l}578.160 \\
479.860\end{array}$ & $\begin{array}{l}578.160 \\
479.860\end{array}$ \\
\hline Cuenca . . . . & 1.383 .720 & 1.391 .840 & 1.167 .820 & 1.167 .820 \\
\hline Alcaraz & 265.910 & 275.210 & 275.910 & 275.910 \\
\hline Murcia & 568.700 & 618.700 & 618.700 & 568.700 \\
\hline Jaén . & 952.320 & 952.320 & 952.330 & 952.330 \\
\hline Córdoba & 2.353 .000 & 2.353 .000 & 2.353 .000 & 2.366 .000 \\
\hline Sevilla. & 4.341 .810 & 4.888 .540 & 4.909 .670 & 4.909 .670 \\
\hline Costas de la mar $\ldots \ldots \ldots$. & 624.000 & - & - & - \\
\hline Prov. León Orden Santiago & 509.000 & 509.000 & 509.000 & 509.000 \\
\hline Trujillo $\ldots$ & 2.062 .520 & 2.035 .420 & 2.035 .420 & 2.035 .420 \\
\hline Ciudad Real & 62.000 & 72.000 & 72.000 & 72.000 \\
\hline Tierras Orden de Calatrava & & 522.000 & 360.000 & 360.000 \\
\hline Tierras duque Medinaceli. & - & - & 216.000 & 216.000 \\
\hline Santander, Laredo y Trasmiera & 72.120 & 72.120 & 72.120 & 72.120 \\
\hline
\end{tabular}

(49) A.G.S. Contaduria del Suelo, $1 .^{\text {a }}$ serie, leg. 53, fol. 2.

(50) A.G.S. Contaduría Mayor de Cuentas, 1. ${ }^{\circ}$ época, leg. 134.

(51). Sin las tierras del marqués de Villafranca.

(52) Incluyendo la mitad de los lugares del duque del Infantado. 


\section{Relación de capitales provinciales}

\begin{tabular}{|c|c|}
\hline 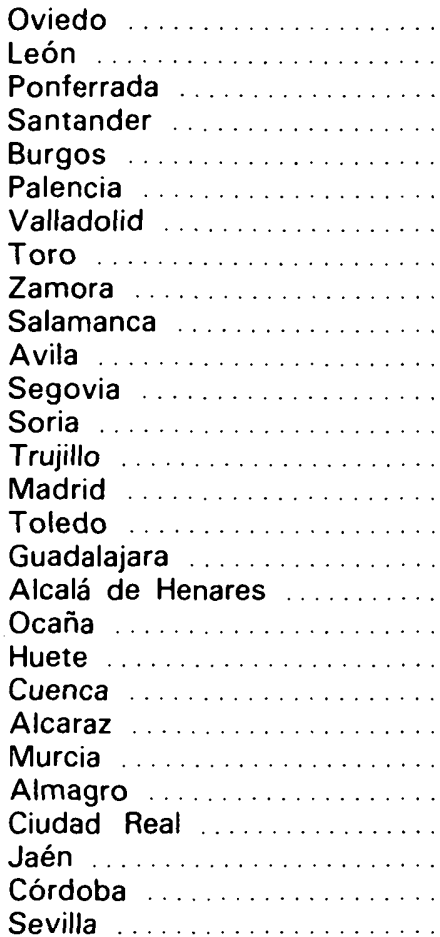 & $\begin{array}{l}\text { Asturias de Oviedo. } \\
\text { León. } \\
\text { Ponferrada. } \\
\text { Santander, Laredo y Trasmiera. } \\
\text { Burgos. } \\
\text { Palencia. } \\
\text { Valladolid. } \\
\text { Toro. } \\
\text { Zamora. } \\
\text { Salamanca. } \\
\text { Avila. } \\
\text { Segovia. } \\
\text { Soria. } \\
\text { Trujillo. } \\
\text { Madrid. } \\
\text { Toledo. } \\
\text { Guadalajara. } \\
\text { Tierras del Arzob. de Toledo. } \\
\text { Prov. de Castilla de la O. de Santiago. } \\
\text { Huete. } \\
\text { Cuenca. } \\
\text { Alcaraz. } \\
\text { Murcia. } \\
\text { Tierras de la O. de Calatrava. } \\
\text { Ciudad Real. } \\
\text { Jaén. } \\
\text { Córdoba. } \\
\text { Sevilla. }\end{array}$ \\
\hline
\end{tabular}

